\title{
Felicidad Urbana. Área Metropolitana del Valle de Aburrá
}

\author{
Urban Happiness Metropolitan Area of the Aburrá Valley \\ Recibido: 14-09-2019 • Aprobado: 07-07-2019 • Página inicial: 113 - Página final: 147 \\ Ángel Emilio Muñoz Cardona*
}

Resumen: la finalidad del presente ensayo de investigación es saber qué tan felices son los jóvenes universitarios de último semestre del área metropolitana del valle de Aburrá, a fin de que los gobiernos conozcan qué tan satisfechos están ellos con sus municipalidades, se pueda reducir la migración califi cada y mejorar la efi ciencia del gasto público en equipamiento de ciudad. La investigación se basa en los índices internacionales de: Bienestar Pluridimensional, Calidad de Vida, Necesidades Básicas, Planeta feliz, Mejor Bienestar de Vida y de Felicidad Integral de la ciudad de Medellín. Para tal efecto, se realizaron 730 cuestionarios bajo el método de análisis multivariado, con un nivel de confianza del $95 \%$ y un margen de error del 5\%. La investigación concluye en la existencia de un equipamiento de ciudad para el bienestar general capaz de retener el $67,89 \%$ de sus jóvenes universitarios.

Palabras clave: calidad de vida, felicidad intersubjetiva, felicidad subjetiva, necesidades básicas insatisfechas, proyecto de vida.
Abstract: how happy the university students of the last semester of the metropolitan area of Aburra Valley. The study aims for governments to know how satisfi ed they are with their municipalities, can reduce qualifi ed migration and improve the effi ciency of public spending on city equipment. The research is based on the international indices of: Multidimensional Wellbeing, Quality of Life, Basic Needs, Happy Planet, Better Life Wellbeing and of Integral Happiness of the city of Medellín. For this purpose, 730 surveys were conducted using the multivariate analysis method, with a confi dence level of $95 \%$ and a margin of error of $5 \%$. The investigation concludes in the existence of a city equipment for the general welfare able to retain $67,89 \%$ of its university students."

Keywords: Intersubjective happiness, life project, quality of life, subjective happiness, Unsatisfi ed Basic Needs.

$$
\text { JEL: H41 - H52 - H53 - H54 - I23 - I30 - }
$$$$
\text { O15 - P25 - R53 }
$$

\footnotetext{
* Economista de la Universidad de Antioquia, Especialista en Economía del Sector Público de la Universidad Autónoma Latinoamericana, Magister en Filosofía Política y Ética de la Universidad de Antioquia, Doctor en Filosofía Civil de la Universidad Pontificia Bolivariana y Postdoctor en Economía Pública de la Vrije Universiteit Amsterdam. Director del Grupo de Investigación Gobierno, Territorio y Cultura de la Escuela Superior de Administración Pública - ESAP, Antioquia, y docente de planta de la misma Institución. angelemil@gmail.com ORCID: https://orcid.org/0000-0001-5008-0983
} 


\section{Contexto Muñoz, A.}

\section{Felicidade urbana Região Metropolitana do Vale do Aburrá}

Resumo: o objetivo deste ensaio de pesquisa é saber quão felizes são os universitários no último semestre de região metropolitana do vale do Aburrá, no final de que os governos sabem o quão satisfeito eles estão com seus municípios pode reduzir a migração qualificada e melhorar a eficiência dos gastos públicos em equipamento da cidade. A investigação Baseia-se nos índices internacionais de: Bem-estar multidimensional, qualidade de vida, Necessidades Básicas, Planeta Feliz, Melhor Bem-estar da vida e felicidade integral da cidade de Medellín. Para esse fim, conduziu 730 questionários sob o método análise multivariada, com um nível de $95 \%$ de confiança e margem de erro de 5\% A investigação conclui na existência de um equipamento urbano para o bem-estar geral capaz de reter $67,89 \%$ de sua Estudantes universitários.

Palavras-chave: qualidade de vida, felicidade felicidade intersubjetiva, subjetiva, necessidades Projeto de vida básico insatisfeito. 
¿Serán los civilizados más felices que los atrasados? Creo que no lo serán ni más ni menos. Lo que ganan por fuera lo pierden por dentro; pues el bien objetivo no siempre produce el subjetivo. La civilización es muy compleja, muy agitada y muy vertiginosa. Por ende, no es propicia para la calma y tranquilidad, y sin ellas no es muy posible la dicha.

Tomás Carrasquilla. La vida. El Espectador, 27 de mayo de 1914.

\section{Introducción}

El área metropolitana del valle de Aburrá, al igual que el modelo administrativo para la planificación del territorio y las Provincias son un modelo interadministrativo de asociatividad público-privado para el desarrollo municipalista y regional sostenible. Afirma el gerente del Área Metropolitana Eugenio Prieto Soto:

El Área avanza en la tarea de hacer realidad la descentralización política, fiscal y administrativa como instrumento para reducir las desigualdades y las inequidades en los territorios y avanzar definitivamente en la búsqueda de un diálogo que rompa las asimetrías entre el centro y las periferias de nuestro territorio (...) la integración es razón de crecimiento local capaz de contrarrestar la soberbia del centralismo administrativo y la desidia de las autonomías locales (2017).

La asociación municipalista con equidad es un modelo de crecimiento en inversiones para la satisfacción de necesidades comunes, en cuanto a movilidad, infraestructura, servicios públicos, vivienda, recreación y esparcimiento, como lo plantea en su recuento histórico del valle de Aburrá (Restrepo, 2011). Asociación interadministrativa que desde 1986 dio vida a la formulación de planes integrados de desarrollo que beneficia a los 10 municipios que conforman el área metropolitana. Los planes integrados de desarrollo son un instrumento de desarrollo en infraestructura o equipamiento de ciudad a largo plazo.

Desde esta perspectiva, la ciudad núcleo del área metropolitana del valle de Aburrá diseñó en el 2016 el índice de felicidad integral para Medellín (IFI) (ver Tabla 1), el cual mide los crecimientos de las experiencias de felicidad sentida de la ciudadanía como resultado de integrar diferentes tipos de bienestar subjetivo: material, social-poblacional, económico, ambiental y personal (psicológico, espiritual y emocional); es decir, mide la percepción que los ciudadanos tienen del mejoramiento de su bienestar de un año a otro a partir de factores objetivos como subjetivos (“En Medellín así es la experiencia...", 2017). 


\section{Contexto Minios, A}

Tabla 1.

Indicadores internacionales de felicidad

\begin{tabular}{|c|c|c|c|c|c|c|c|c|}
\hline Variables e Indicadores & HPI & SPI & $\mathrm{BP}$ & ICV & BLI & IFN & IFI & DANE \\
\hline 1. Salud con calidad & & $\mathrm{x}$ & $\mathrm{x}$ & $\mathrm{x}$ & $\mathrm{x}$ & $\mathrm{x}$ & $\mathrm{x}$ & \\
\hline 2. Educación con calidad & & $\mathrm{x}$ & $\mathrm{x}$ & $\mathrm{x}$ & $\mathrm{x}$ & $\mathrm{x}$ & $\mathrm{x}$ & \\
\hline 3. Diversidad ambiental & $\mathrm{x}$ & $\mathrm{x}$ & $\mathrm{x}$ & $\mathrm{x}$ & $\mathrm{x}$ & $\mathrm{x}$ & $\mathrm{x}$ & $\mathrm{x}$ \\
\hline 4. Nivel o costo de vida & $\mathrm{x}$ & $\mathrm{x}$ & $\mathrm{x}$ & $\mathrm{x}$ & $\mathrm{x}$ & $\mathrm{x}$ & & $\mathrm{x}$ \\
\hline 5. Gobernanza y transparencia & $\mathrm{x}$ & & $\mathrm{x}$ & & $\mathrm{x}$ & $\mathrm{x}$ & $\mathrm{x}$ & \\
\hline 6. Bienestar de la población & & $\mathrm{x}$ & & & & $\mathrm{x}$ & $\mathrm{x}$ & $\mathrm{x}$ \\
\hline 7. Uso del tiempo libre & & $\mathrm{x}$ & & & & $\mathrm{x}$ & $\mathrm{x}$ & \\
\hline 8. Vitalidad comunitaria, tolerancia e inclusión & & $\mathrm{x}$ & $\mathrm{x}$ & & $\mathrm{x}$ & $\mathrm{x}$ & $\mathrm{x}$ & \\
\hline 9. Cultura & & & & & & $\mathrm{x}$ & $\mathrm{x}$ & \\
\hline 10. Nivel de Ingresos & $\mathrm{x}$ & & $\mathrm{x}$ & & $\mathrm{x}$ & & & $\mathrm{x}$ \\
\hline 11. Desempleo y empleo & & $\mathrm{x}$ & $\mathrm{x}$ & & $\mathrm{x}$ & $\mathrm{x}$ & & $\mathrm{x}$ \\
\hline 12. NBI & & $\mathrm{x}$ & $\mathrm{x}$ & $\mathrm{x}$ & $\mathrm{x}$ & & & $\mathrm{x}$ \\
\hline 13. Satisfacción con la vida o Proyecto de vida & & $\mathrm{x}$ & & & $\mathrm{x}$ & & $\mathrm{x}$ & \\
\hline 14. Esperanza de vida & $\mathrm{x}$ & & & $\mathrm{x}$ & $\mathrm{x}$ & & & $\mathrm{x}$ \\
\hline 15. Movilidad y seguridad & & & $\mathrm{x}$ & $\mathrm{x}$ & $\mathrm{x}$ & & $\mathrm{x}$ & $\mathrm{x}$ \\
\hline 16. Precio de la propiedad & & & & $\mathrm{x}$ & & & & \\
\hline
\end{tabular}

Grupo de Investigación: Gobierno, Territorio y Cultura. ESAP, COLCIENCIAS.

Indicadores: HPI: Happy Planet Index; SPI: Social Progress Index; BP: Bienestar Pluridimensional; ICV: Índice de Calidad de Vida; BLI: Better Life Index; IFN: Índice de Felicidad Nacional; IFI: Índice de Felicidad Integral (DANE, 2016)

Basados en indicadores internacionales de felicidad (Tabla 1), el grupo de investigación Gobierno, Territorio y Cultura realizó un estudio a tres áreas metropolitanas: valle de Aburrá, Eje Cafetero y Santanderes. Para el estudio de la felicidad urbana del valle de Aburrá se tomó como muestra la población universitaria de los últimos semestres. La razón es conocer cómo ven los jóvenes próximos a ser profesionales el futuro de su región, qué tan felices son de vivir en sus ciudades, y cómo ven la realización de sus proyectos de vida en sus localidades. 


\section{Metodología}

En conformidad con lo anterior la hipótesis de investigación es la siguiente:

A mayor migración de la población joven de un municipio por falta de oportunidades para la autorrealización, menores son las posibilidades de desarrollo y crecimiento municipales. Por el contrario, a menor migración de la población joven de un municipio por buenas y abundantes oportunidades para la autorrealización, mayores son las posibilidades de desarrollo y crecimiento del municipio y sus localidades.

Para demostrar dicha hipótesis se elaboró un instrumento de encuesta con 44 preguntas agrupadas en tres grandes variables. La variable $\mathrm{P}_{1}$ agrupa 14 preguntas y posee un peso estadístico del $40 \%$. En este conjunto de preguntas se hace una caracterización demográfica, se busca conocer qué bienes públicos y qué calidad de estos disfrutan los estudiantes de último semestre universitario para el logro de una vida digna. La variable $\mathrm{P}_{2}$ agrupa 14 preguntas y posee un peso estadístico del $30 \%$. En este conjunto de preguntas se evalúa la satisfacción con los recursos y servicios municipales ofertados, se busca conocer el nivel de satisfacción de los estudiantes de último semestre universitario con su familia, la vivienda, el vecindario, los recursos naturales y los espacios públicos para la movilidad -aceras peatonales, señalización de vías y vías pavimentadas-. La variable $\mathrm{P}_{3}$ agrupa 16 preguntas que evalúan el reconocimiento y las relaciones de pertinencia con la comunidad. En esta variable se toma en cuenta qué tanto participa el joven universitario de últimos semestres en el crecimiento y desarrollo de su comunidad. $\mathrm{P} 3$ posee un peso estadístico del 30\%.

A través de dicho instrumento de encuesta se analiza qué tanto pueden los jóvenes universitarios realizar su proyecto de vida con el desarrollo municipalista alcanzado. En otras palabras, ¿qué bienestar general disfrutan ellos en sus localidades capaces de crear vínculos de permanencia?, es decir, ¿son felices los jóvenes del valle de Aburrá y por qué lo son? El estudio concluye en un nivel de satisfacción de 1 a 5 , que la población joven calificada del valle de Aburrá posee una felicidad intersubjetiva de 4.05.

Finalmente, antes de dar comienzo a los resultados del estudio es necesario aclarar que el valle de Aburrá está integrado por 10 municipios, pero en el imaginario de los habitantes no existen divisiones políticas geográficas. El área metropolitana es en realidad una gran ciudad conformada por " 10 barrios" en los que viven más de 3.700 .000 personas. El transporte público del Metro con todos sus sistemas integrados -Tranvía, Metrocable y busetas- facilita la 


\section{Contexto minos a}

movilidad de miles de estudiantes a todas las universidades de la región, incluso de municipios que no son parte del área metropolitana pero que desarrollan su diario vivir como si lo fueran, tal es el caso de los municipios del Oriente, el Occidente y el Suroeste antioqueños, como Amagá, San Pedro de los Milagros, Rionegro, Marinilla, La Ceja y todos los corregimientos cercanos. En el área metropolitana los antioqueños viven y disfrutan de las instituciones de salud, educación y trabajo como una misma familia (El Colombiano, 2017).

\section{Distribución poblacional}

La muestra poblacional se tomó de universidades, tanto públicas como privadas, con presencia en cada municipio y que permitieron el acceso de los investigadores. Para el análisis, los estratos socioeconómicos 1 y 2 son bajos, 3 y 4 son medios y 5 y 6 son altos. Por lo tanto, del total de la muestra de 720 estudiantes de último semestre universitario el $28,19 \%$ fueron de estrato socioeconómico bajo, el $65,55 \%$ de estrato medio y el $4,16 \%$ de estrato alto (ver Tabla 2 ).

Tabla 2.

Población de la muestra por estrato socioeconómico

\begin{tabular}{cccc}
\hline Valle de Aburrá & Hombres & Mujeres & Total general \\
\hline & 389 & 331 & 720 \\
\hline Estrato 1 & 11 & 9 & 20 \\
\hline Estrato 2 & 107 & 76 & 183 \\
\hline Estrato 3 & 192 & 167 & 359 \\
\hline Estrato 4 & 56 & 57 & 113 \\
\hline Estrato 5 & 14 & 11 & 25 \\
\hline Estrato 6 & 1 & 4 & 5 \\
\hline $\mathrm{N} / \mathrm{R}$ & 8 & 7 & 15 \\
\hline Total general & 389 & 331 & 720 \\
\hline
\end{tabular}

Centro de Estudios Económicos Regionales (CEER) de la ESAPy grupo de investigación Gobierno, Territorio y Cultura de Antioquia.

El tamaño de la muestra tomada entre jóvenes universitarios de último semestre garantiza un índice de confianza estadístico del 95\% con un margen de error del 5\%. El 54\% de los jóvenes estudiantes encuestados fueron hombres y el $46 \%$, mujeres. La población femenina, distribuida entre las diferentes carreras de formación profesional (ingeniería, matemáticas, medicina, economía, administración de empresas, etc.), se concentra en los estratos socioeconómicos 2, 3 y 4. En los estratos socioeconómicos bajo y medio se concentra el 93,75\% de la población de la muestra. 
En otras palabras, el área metropolitana del valle de Aburrá concentra en su población joven universitaria estudiantes de estratos socioeconómicos bajo y medio, lo que ayuda al mejoramiento de la calidad de vida de los más pobres, como bien lo demanda el Índice Internacional de Desarrollo Humano (IDH) del Programa de las Naciones Unidas par el Desarrollo (PNUD) y el índice de calidad de vida (ICV) de Planeación Nacional (Muñoz, 2018, p.93).

Tabla 3.

Población de la muestra por edad

\begin{tabular}{cccccc}
\hline Edad & $\mathrm{E}<20$ & $20<\mathrm{E}<29$ & $30<\mathrm{E}<39$ & $\mathrm{E}>40$ & Total general \\
\hline Valle de Aburrá & 96 & 520 & 90 & 24 & 730 \\
\hline Total general & $13,15 \%$ & $71,23 \%$ & $12,32 \%$ & $3,28 \%$ & $100 \%$ \\
\hline
\end{tabular}

Centro de Estudios Económicos Regionales (CEER) de la ESAP y grupo de investigación Gobierno, Territorio y Cultura de Antioquia.

De los 730 estudiantes universitarios encuestados en el área metropolitana del valle de Aburra, 10 no pertenecían al área ni al departamento y respondieron las preguntas de acuerdo con las características de sus territorios, por lo que no se tuvieron en cuenta. El 71,23\% de los estudiantes de último semestre del área metropolitana están entre los 20 y 29 años, el 13,15\% eran menores de 20 años, el 12,32\% tenían entre 30 y 39 años y el 3,3\%, más de 40 años. En otras palabras, la población universitaria encuestada es principalmente joven con alta formación académica (ver Tabla 3).

Tabla 4.

Densidad poblacional per cápita

\begin{tabular}{cc}
\hline Área Metropolitana del Valle de Aburrá & ¿Cuántas personas viven con usted? \\
\hline 1 persona & $13,0 \%$ \\
\hline 2 personas & $23,2 \%$ \\
\hline 3 personas & $34,4 \%$ \\
\hline 4 personas & $16,7 \%$ \\
\hline 5 personas & $5,1 \%$ \\
\hline 6 personas & $3,0 \%$ \\
\hline 7 persona o más & $1,4 \%$ \\
\hline Vive solo & $3,3 \%$ \\
\hline Total general & $100,0 \%$ \\
\hline
\end{tabular}

Centro de estudios económicos regionales CEER de la ESAP y grupo de investigación Gobierno, Territorio y Cultura de Antioquia. 


\section{Contexto minosid}

El $87,3 \%$ de los hogares de las familias de los estudiantes universitarios de último semestre están conformados principalmente hasta 4 personas. La conformación más frecuente es de tres personas, es decir, el $34,4 \%$ de los hogares principalmente de estrato socioeconómico bajo y medio es de tres personas. El 9,6\% de los hogares están conformados por más de cuatro personas. En otras palabras, la conformación del hogar típico promedio de los jóvenes universitarios de último semestre es de 2 a 3 personas (ver Tabla 4).

El 2,4\% de los estudiantes universitarios de último semestre del valle de Aburrá viven en corregimientos, el 5,7\% en zonas rurales y el $91,8 \%$ en zona urbana. De igual manera, el estudio de investigación mostró que el $89,51 \%$ de los jóvenes calificados viven con familia y familiares muy cercanos. Solo el 7,41\% viven con amigos o acogidos, es decir, en residencias u apartamentos universitarios. De acuerdo con la anterior distribución poblacional, ¿cuáles son los índices de necesidades básicas insatisfechas (NBI)?

\section{Resultados}

\section{Primer indicador de NBI: Caracterización y satisfacción con la vivienda}

De acuerdo con la Tabla 5, el 62,4\% de los jóvenes universitarios de último semestre del área metropolitana del valle de Aburrá viven en vivienda propia y familiar, es decir que poseen una relativa tranquilidad habitacional (ver Tabla 5). El 36,86\% viven en viviendas arrendadas, de ellos el 3\% afirman vivir solos. El 1,9\% viven en viviendas prestadas, es decir que viven en condiciones habitacionales más inestables. En general, más del $98 \%$ de los jóvenes calificados disfrutan de relativa tranquilidad habitacional, están en el nivel 4 de la pirámide de la satisfacción de las necesidades de Abraham Maslow (2008): el reconocimiento.

Tabla 5.

NBI. Caracterización de la vivienda

\begin{tabular}{cccccc}
\hline ¿Su vivienda es? & \multicolumn{3}{c}{$\begin{array}{c}\text { Material de las } \\
\text { paredes }\end{array}$} & \multicolumn{3}{c}{$\begin{array}{c}\text { Material del } \\
\text { piso }\end{array}$} \\
\hline Propia & $47,83 \%$ & Ladrillo o bloque & $96,6 \%$ & Baldosa & $58,83 \%$ \\
\hline Arrendada & $36,86 \%$ & Madera y lata & $0,5 \%$ & Cemento & $3,26 \%$ \\
\hline Familiar & $13,41 \%$ & Tapia u otro & $2 \%$ & Cerámica & $35,60 \%$ \\
\hline Prestada & $1,90 \%$ & N/R & $0,8 \%$ & Otros & $2,3 \%$ \\
\hline Total general & $100,00 \%$ & Total general & $100.0 \%$ & Total general & $100,00 \%$ \\
\hline
\end{tabular}

Centro de estudios económicos regionales CEER de la ESAP y grupo de investigación Gobierno, Territorio y Cultura de Antioquia. 
En cuanto a los materiales de la vivienda, el 96,6\% de los jóvenes calificados viven en casas de construcción con material de playa, es decir, son construcciones modernas. Incluso el 94,43\% viven en viviendas con pisos en material de baldosa y cerámica. Solo el 2,5\% viven en casas construidas en madera, lata, tapia u otro y el 2,3\% con pisos en otros materiales de construcción diferentes a los de playa (ver Tablas 5 y 7 ).

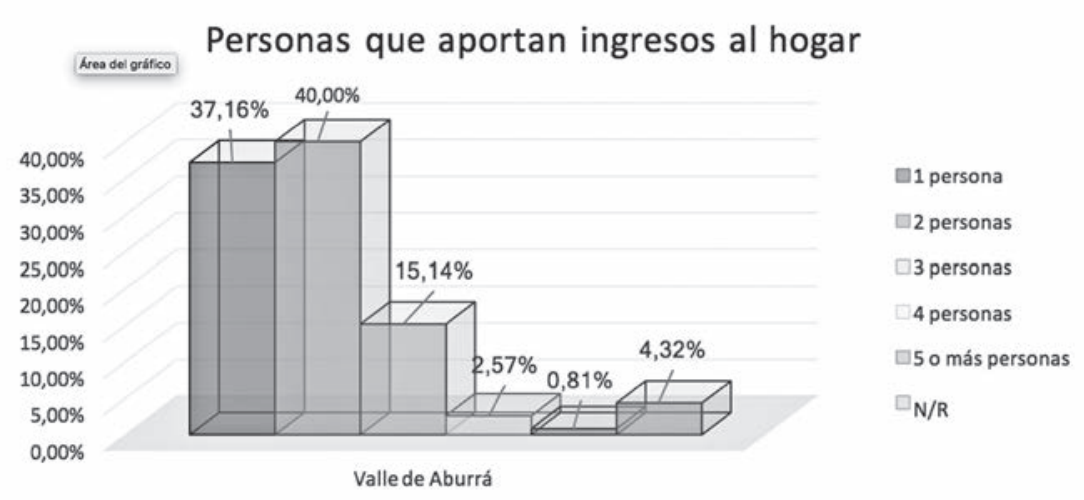

Figura 1. NBI. Aportes de ingresos al hogar.

Centro de estudios económicos regionales CEER de la ESAP y grupo de investigación Gobierno, Territorio y Cultura de Antioquia.

En la evaluación de NBI, según aportes de ingresos al sostenimiento del hogar, el $40 \%$ de los hogares de los jóvenes universitarios de último semestre reciben aportes de dos personas, dato que por sí solo es muy significativo si se toma en cuenta que el $89,51 \%$ viven con la familia, la composición de los hogares en promedio es de 3 personas y son de estrato socioeconómico bajo y medio (Figura 1).

El 37,16\% de los hogares de los estudiantes de último semestre universitario en el área metropolitana son sostenidos económicamente por una sola persona y el $15,14 \%$, por tres personas. Es decir, los hogares de los jóvenes calificados (93,75\% de estratos bajo y medio) gozan de relativa estabilidad económica, lo que les permite, en términos del psicólogo Abraham Maslow, estar en la cuarta escala de la pirámide de las necesidades y aspirar al último eslabón de la autorrealización personal de sus sueños (Maslow, 2008). 


\section{Contexto Munosed}

Tabla 6.

NBI. Asignación habitacional

\begin{tabular}{ccc}
\hline Satisfacción con la amplitud de la vivienda & Valle de Aburrá & Total general \\
\hline 1 (Poco satisfecho) & $2,6 \%$ & $2,6 \%$ \\
\hline 2 & $1,8 \%$ & $1,8 \%$ \\
\hline 3 & $13,0 \%$ & $13,0 \%$ \\
\hline 4 & $34,8 \%$ & $34,8 \%$ \\
\hline 5 (Muy satisfecho) & $47,8 \%$ & $47,8 \%$ \\
\hline Total general & $100,0 \%$ & $100,0 \%$ \\
\hline
\end{tabular}

Centro de estudios económicos regionales CEER de la ESAP y grupo de investigación Gobierno, Territorio y Cultura de Antioquia.

Para conocer el grado de asignación habitacional, se preguntó por el nivel de satisfacción con la amplitud de la vivienda. El 82,6\% afirman estar satisfechos y muy satisfechos, el 13\% afirman estar regularmente satisfechos. Es decir, el 95,8\% están bien; lo que confirma la hipótesis de relativa estabilidad del joven calificado en la vivienda que conforma su hogar, de hecho, el $87,8 \%$ de ellos afirman estar satisfechos y muy satisfechos viviendo con su familia y familiares. El 8,1\% afirman estar regularmente satisfechos; por lo que allí puede concentrarse el índice de NBI sobre la asignación habitacional.

En resumen, los indicadores sobre caracterización y satisfacción con la vivienda, en su conjunto, reafirman el estado de satisfacción de los jóvenes universitarios con la casa, los familiares y los ingresos del hogar. Para el caso del área metropolitana del valle de Aburrá, la unión de los 10 municipios ha logrado reducir el porcentaje de las NBI a un solo dígito desde el año 2009 al 2018. Del 2009 al 2015, tanto en el Aburrá Norte como en el Sur el porcentaje de familias con NBI se redujo en más de un 300\% (ver Tabla 7).

En otras palabras, los programas gubernamentales para el mejoramiento de vivienda y de subsidios para vivienda de interés prioritario y de interés social han dado buenos resultados en cuanto a reducción de hacinamiento crítico y de viviendas inadecuadas o sin servicios públicos domiciliarios $(<1 \%)$, es decir, en los 10 municipios que integran el valle de Aburrá menos del $11 \%$ de las familias urbanas y rurales viven en viviendas con déficit cualitativo, esto es, en viviendas que requieren mejoras bien sea por hacinamiento, materiales de construcción precarios, falta de servicios públicos o una combinación de las anteriores (ver Tabla 7). 
Tabla 7.

NBI y porcentaje de hogares en condiciones no adecuadas

\begin{tabular}{|c|c|c|c|c|c|}
\hline Área Metropolitana & \multicolumn{4}{|c|}{ Porcentaje de hogares con: } & \multirow{2}{*}{$\begin{array}{c}\text { satisfacción } \\
2018\end{array}$} \\
\hline Año & 2009 & 2011 & 2013 & 2015 & \\
\hline Total Aburrá Norte. NBI & 19,3 & 15 & 10,9 & 4,3 & \\
\hline Total Aburrá Sur. NBI & 9 & 10,8 & 7,3 & 2,7 & \\
\hline Total Centro. NBI & 5,6 & 7,5 & 3,1 & 1,7 & \\
\hline \multicolumn{5}{|c|}{ Hogares con NBI } & 2,12 \\
\hline Total Aburrá Norte. PHVSSP* & 14,7 & 5,5 & 7,4 & 1,9 & \\
\hline Total Aburrá Sur. PHVSSP & 4 & 3 & 4,3 & 0,9 & \\
\hline Total Centro. PHVSSP & 0,2 & 0,2 & 0,4 & 0,4 & \\
\hline \multicolumn{5}{|c|}{ Satisfacción servicios públicos } & $86,2(4$ y 5$)$ \\
\hline Total Aburrá Norte. PHHC & 2,8 & 2,1 & 1,9 & 0,2 & \\
\hline Total Aburrá Sur. PHHC & 2,4 & 1,3 & 1,5 & 0,3 & \\
\hline Total Centro. PHHC & 3,1 & 1,6 & 1,5 & 0,1 & \\
\hline \multicolumn{5}{|c|}{ Satisfacción espacios de la vivienda } & $82,6(4$ y 5$)$ \\
\hline Total Aburrá Norte. PHVID & 0,9 & 1,4 & 0,7 & 0,6 & \\
\hline Total Aburrá Sur. PHVID & 0,1 & 0,3 & 0,3 & 0,4 & \\
\hline Total Centro. PHVID & 0,7 & 1,2 & 0,2 & 0,2 & \\
\hline \multicolumn{5}{|c|}{ Hogares sin déficit cualitativo } & 96,6 \\
\hline Total Aburrá Norte PVDCL & 14,1 & 35,1 & 14,9 & 11,3 & \\
\hline Total Aburrá Sur PVDCL & 5,5 & 16,2 & 10,1 & 7,0 & \\
\hline Total Centro PVDCL & 0,9 & 0,9 & 5,1 & 10,8 & \\
\hline \multicolumn{5}{|c|}{ Hogares con déficit cualitativo } & 3,4 \\
\hline
\end{tabular}

* PHHC: Porcentaje de Hogares en Hacinamiento Crítico, más de 3 personas por cuarto . PHVID: Porcentaje de Hogares en viviendas inadecuadas; en general, se consideran viviendas móviles, refugios naturales o sin paredes. En las zonas urbanas, además, se tienen en cuenta las viviendas con piso de tierra o material en paredes de bahareque sin revocar. PHVSSP: Porcentaje de Hogares en viviendas sin conexión a servicios públicos de acueducto o alcantarillado para el área urbana y hogares sin conexión a servicios públicos de acueducto, alcantarillado o pozo séptico en el área rural. . NBI es el índice de Necesidades Básicas Insatisfechas. PVDCL: es el porcentaje de los hogares con déficit cualitativo, VDCL significa viviendas con déficit cualitativo. Y TV es el Total de viviendas.

Oficina de Planeación del Área Metropolitana del Valle de Aburrá, Centro de estudios económicos regionales CEER de la ESAP y grupo de investigación Gobierno, Territorio y Cultura de Antioquia. 1 es poco satisfecho, 5 es muy satisfecho y 3, regularmente satisfecho. 


\section{Contexto Muroza, $A$.}

Para el 2018, los hogares del área metropolitana con NBI de los jóvenes universitarios encuestados fueron el 2,12\%, principalmente por falta de cobertura en la red de gas domiciliario $(4,39 \%)$ y del servicio de internet $(2,9 \%)$. Lo que muestra un excelente comportamiento de cobertura en la gran ciudad del área metropolitana.

De igual manera ocurre con el mejoramiento de las condiciones habitacionales de la vivienda familiar en el valle de Aburrá. En otras palabras, las políticas de mejoramiento de vivienda y de subsidios a la vivienda de interés prioritario y de interés social han dado buenos resultados en: reducción de hacinamiento crítico y de viviendas inadecuadas o sin servicios públicos domiciliarios $(<1 \%)$, o sea que en los 10 municipios que integran el valle de Aburrá menos del $11 \%$ de las familias urbanas y rurales viven en viviendas con déficit cualitativo, es decir, en viviendas que requieren mejoras bien sea por hacinamiento, materiales de construcción precarios, falta de servicios públicos o una combinación de las anteriores (ver Tabla 7).

En el 2018, el 82,6\% de los jóvenes universitarios calificados afirman estar satisfechos y muy satisfechos con la amplitud de los espacios que disfrutan en sus viviendas. El 13\% de estos estudiantes universitarios afirman estar regularmente satisfechos. Estos datos corroboran el mejoramiento de la vivienda en el valle de Aburrá.

En el 2018, el 86,2\% de los jóvenes calificados manifiestan estar satisfechos y muy satisfechos con la calidad de los servicios públicos domiciliarios que ellos reciben, el $11 \%$ afirman estar regularmente satisfechos, solo un $2,8 \%$ dicen recibir mala calidad del servicio.

Esto permite afirmar que para el 2018 la calidad en la cobertura en los servicios públicos domiciliarios sigue siendo alta dentro del área metropolitana del valle de Aburrá (ver Tabla 7).

\section{Otros indicadores de equipamiento de ciudad: La salud y la seguridad social}

Para el caso del área metropolitana del valle de Aburrá la justicia en lo social se ha convertido en un tema fundamental de apropiación del territorio, que facilita el amor por el territorio y sus instituciones. El amor de los antioqueños por sus localidades facilita la inversión pública y su conservación, el aseo de la ciudad y el uso responsable de los recursos comunes (ver Tabla 8). 
El área metropolitana, en unión con el sector privado y los centros de investigación de las universidades con programas de medicina, ofertan una buena red hospitalaria con la que se logra cubrir a más del $90 \%$ de la población ocupada y afiliada a seguridad social en salud. De hecho, el 96,7\% de los jóvenes estudiantes encuestados reconocen que en sus municipios hay hospitales con servicio de hospitalización, y más del $94,1 \%$ están afiliados a seguridad social en salud.

De igual manera, gracias al clúster de la salud producto de la integración administrativa y universitaria de los 10 municipios, el área metropolitana del valle de Aburrá es líder en investigación médica sobre el alzheimer y atención estética y quirúrgica para el trasplante de órganos como: corazón, riñones, esfínter y pulmón; con lo que se logra mejores coberturas de calidad en salud.

Tabla 8.

Seguridad social

\begin{tabular}{lcccc}
\hline \multicolumn{1}{c}{ Área Metropolitana } & \multicolumn{5}{c}{ Población ocupada afiliada a riesgos profesionales* } \\
\hline \multicolumn{1}{c}{ Año } & 2009 & 2011 & 2013 & 2015 \\
\hline Total Aburrá Norte & 34,4 & 50,3 & 56,8 & 53,9 \\
\hline Total Aburrá Sur & 41,9 & 57,8 & 67,0 & 58,0 \\
\hline Total Centro & 42,9 & 52,6 & 51,8 & 57,9 \\
\hline Área Metropolitana & \multicolumn{5}{c}{ Población ocupada afiliada a salud** } \\
\hline Total Aburrá Norte & 82,6 & 89,2 & 93,6 & 95,9 \\
\hline Total Aburrá Sur & 79,8 & 92,8 & 95,6 & 88,0 \\
\hline Total Centro & 83,8 & 92,7 & 94,9 & 96,2 \\
\hline Área Metropolitana & Población afiliada al sistema de seguridad social en salud*** & 93,2 \\
\hline Total Aburrá Norte & 80,4 & 86,1 & 92,0 & 85,9 \\
\hline Total Aburrá Sur & 75,3 & 90,8 & 92,3 & 93,8 \\
\hline Total Centro & 80,4 & 90,7 & 93,6 & 18,7 \\
\hline Área Metropolitana & \multicolumn{2}{c}{ Población afiliada al régimen subsidiado en salud**** } \\
\hline Total Aburrá Norte & 32,7 & 30,8 & 35,5 & 26,4 \\
\hline Total Aburrá Sur & 15,1 & 24,2 & 22,1 & 17,4 \\
\hline Total Centro & 24,5 & 26,5 & 29,4 & \\
\hline
\end{tabular}




\begin{tabular}{|c|c|c|c|c|}
\hline Área Metropolitana & \multicolumn{4}{|c|}{ Población ocupada afiliada a riesgos profesionales* } \\
\hline Área Metropolitana & \multicolumn{4}{|c|}{ Población Ocupada afiliada a pensiones $* * * * *$} \\
\hline Total Aburrá Norte & 40,9 & 52,0 & 57,7 & 54,7 \\
\hline Total Aburrá Sur & 48,9 & 60,0 & 8,9 & 61,6 \\
\hline Total Centro & 47,5 & & 53,3 & 65,7 \\
\hline \multicolumn{5}{|c|}{$\begin{array}{l}\text { * Es la relación de la población ocupada afiliada a riesgos profesionales respecto a población ocupada. POAR: } \\
\text { Población ocupada afiliada a riesgos profesionales. PO: Población ocupada; corresponde a la población con } \\
\text { alguna de las siguientes características 1) Ejercieron una actividad en la producción de bienes y servicios } \\
\text { con por lo menos una hora remunerada a la semana, 2) Los trabajadores familiares sin remuneración que } \\
\text { trabajaron por lo menos } 15 \text { horas a la semana y } 3 \text { ) las personas que no trabajaron, pero tenían un empleo o } \\
\text { trabajo (estaban vinculadas a un proceso de producción cualquiera). } \\
\text { ** El indicador mide la porción de población ocupada que cotiza a sistema de seguridad social en salud. } \\
\text { POAS: Población ocupada afiliada a la salud. PO: Población ocupada. } \\
\text { *** El indicador permite observar qué porción de la población tiene acceso a los servicios de salud por medio } \\
\text { del régimen contributivo o subsidiado. PASS: Personas afiliadas al sistema de seguridad social en salud. PT: } \\
\text { Población total. } \\
\text { **** Es la relación de la población que se encuentra afiliada al sistema de salud Régimen Subsidiado, con } \\
\text { respecto a la población total. PASSS: Personas afiliadas al sistema de seguridad social en salud, régimen } \\
\text { subsidiado. PT: Población total. } \\
* * * * \text { El indicador mide la porción de población ocupada que cotiza al sistema de seguridad social en } \\
\text { pensión. POAP: Población ocupada afiliada a pensiones. PO: Población ocupada. }\end{array}$} \\
\hline
\end{tabular}

Oficina de Planeación del Área Metropolitana del Valle de Aburrá, Centro de estudios económicos regionales CEER de la ESAP y grupo de investigación Gobierno, Territorio y Cultura de Antioquia.

Para tratar los problemas de salud el Gobierno nacional y el departamental con sus empresas descentralizadas ofrecen el Sisbén; programa de cobertura en salud que aplica para personas con patrimonios inferiores a los $\$ 50.000 .000$. Madres cabeza de hogar, población mayor de 60 años, niños, desplazados, desmovilizados, vendedores ambulantes, empleadas de servicio, en general personas de estratos 1 y 2 . Más del $60 \%$ de la población ocupada en el área metropolitana está afiliada a pensiones y más del $50 \%$, a riesgos profesionales (Tabla 8). Indicadores que, si bien son buenos en relación con los del resto del país, deben ser mejorados al 100\%. Las cajas de compensación como Comfama crearon el subsidio al desempleo para personas cabezas de hogar con más de dos hijos y que lleven un año o más sin empleo. 
Tabla 9.

Satisfacción con la atención en salud en el valle de Aburrá

\begin{tabular}{ccc}
\hline Satisfacción & Atención en salud & Programas sociales \\
\hline 1 & $5,8 \%$ & $10,8 \%$ \\
\hline 2 & $7,0 \%$ & $6,7 \%$ \\
\hline 3 & $24,5 \%$ & $26,9 \%$ \\
\hline 4 & $32,9 \%$ & $28,0 \%$ \\
\hline 5 & $29,8 \%$ & $27,7 \%$ \\
\hline Total general & $100 \%$ & $100 \%$ \\
\hline
\end{tabular}

Centro de estudios económicos regionales CEER de la ESAP y grupo de investigación Gobierno, Territorio y Cultura de Antioquia. 1 es poco satisfecho, 5 es muy satisfecho y 3 regularmente satisfecho.

Ante la pregunta en el 2018 a los jóvenes universitarios de último semestre del valle de Aburrá: ¿qué tan satisfechos están con la atención en salud? El 62,7\% afirman estar satisfechos y muy satisfechos, lo cual se refuerza con la satisfacción expresada en relación con los programas sociales de salud de muy buena (ver Tabla 9), y el 24,5\% afirman estar regularmente satisfechos; es decir que el $86,3 \%$ de los habitantes del valle de Aburrá manifiestan tener buenos servicios de salud. El 12,8\% respondieron estar insatisfechos y muy insatisfechos con la atención en salud, porcentaje que, si bien es significativo, no descalifica el buen servicio de cobertura que tienen los habitantes del área metropolitana.

El 55,7\% de los jóvenes universitarios manifiestan estar satisfechos y muy satisfechos con los programas sociales en salud, pero el 44,3\% manifiestan estar regularmente satisfechos y muy insatisfechos. Esta evaluación de insatisfacción invita a las administraciones públicas del área a mejorar en la calidad de los programas sociales de salud que se ofrecen, y en las campañas educativas para la reducción del consumo de tabaco y licor, la ludopatía, y sobre higiene y responsabilidad sexual.

\section{Felicidad intersubjetiva}

De los índices propuestos para medir el grado de felicidad o de bienestar general en contraste con el de producción o PIB están: el Happy Planet Índex realizado por la New Economics Foundation (NEF), al cual se han añadido otros como el Social Progress Index, del economista Michael Porter (ver Tabla 1). Más recientemente, economistas del utilitarismo contemporáneo entienden el 


\section{Contexto minosid}

concepto bienestar de la comunidad como satisfacción de condiciones de vida digna, en otras palabras, de felicidad general, por lo que ven en el Índice de Felicidad Nacional (IFN), propuesto por el país de Bhután, en comparación con el indicador de crecimiento económico del Producto Interno Bruto, uno de los más completos, como lo afirma el Informe sobre la Medición del Desarrollo Económico (CMPEPS) (Stiglitz, Sen y Fitoussi, 2015). Miremos algunos de ellos:

\section{Índice de Condiciones de Vida (ICV)}

El Departamento Nacional de Planeación (DNP) complementa el índice de las NBI utilizando el ICV, con ello busca evaluar, principalmente, la calidad de los bienes que disfrutan las familias colombianas. Si el índice de la calidad de vida aumenta significa que cada vez más familias disfrutan de bienes básicos fundamentales. En otras palabras, la pobreza disminuye. La fórmula de cálculo es la siguiente:

$$
\begin{gathered}
I C V: M P A+M P I+H C+L A+S S+R B+T E+N V H+E J H+E C Y+ \\
C E+P A F+P M 12+P M 18+P M 6+S G S J H+P S G S^{1}
\end{gathered}
$$

Para el caso de los 10 municipios que integran el área metropolitana, la calidad en los servicios públicos domiciliarios es tanto urbana como rural; incluso va más allá, porque se brinda a los demás municipios de Antioquia cobertura y subsidio al consumo de bienes públicos domiciliarios con calidad a través del Grupo EPM, el Área Metropolitana, la Gobernación de Antioquia y las diferentes alianzas público-privadas intermunicipales.

En el área metropolitana muy pocas viviendas carecen de servicios públicos de acueducto, alcantarillado, aseo y energía eléctrica. El 95\% de las familias del área urbana y el $85 \%$ del área rural disfrutan de calidad en el suministro del servicio (ver Tabla 10). Para el 2015, en servicio de internet y gas natural un poco más del $50 \%$ de las familias contaban con dicho servicio domiciliario.

Características de la vivienda: Material predominante de las paredes (MPA), Material predominante de los pisos (MPI), Hacinamiento (HC). Acceso a los servicios públicos: Lugar de donde toma el agua la vivienda (LA), Servicio sanitario que utilizan (SS), Recolección de Basuras (RB). Bienes Muebles: Total de electrodomésticos (TE), Número de vehículos (NVH). Capital humano: Escolaridad del jefe o la persona cabeza del Hogar (EJH), Escolaridad del cónyuge del jefe o cabeza del Hogar (ECY), Carga económica (CE)- Personas ocupadas/Personas en el hogar-, Proporción de analfabetas (PAF), Proporción de menores entre 6 y 12 años que no estudian (PM12), Proporción de menores entre 13 y 18 años que no estudian (PM18). Aspectos demográficos: Proporción de menores de 6 años (PM6). Seguridad Social: Seguridad social del jefe o cabeza del hogar (SGSJH), Proporción de personas en el hogar con seguridad social (PSGS). 
Las familias que no cuentan con el internet domiciliario están parcialmente cubiertas con el internet gratuito que ofrecen las administraciones públicas, los centros comerciales, los parques biblioteca, los centros educativos, la telefonía móvil y las universidades.

Tabla 10.

ICV. Servicios públicos básicos

\begin{tabular}{|c|c|c|c|c|c|c|}
\hline Área Metropolitana & \multicolumn{4}{|c|}{ Cobertura residencial en acueducto* } & \multicolumn{2}{|c|}{2018} \\
\hline Año & 2009 & 2011 & 2013 & 2015 & $\mathrm{Si}$ & No \\
\hline Total Aburrá Norte & 90,9 & 94,5 & 90,1 & 91,8 & \multirow{3}{*}{99,5} & \multirow{3}{*}{0,5} \\
\hline Total Aburrá Sur & 96,2 & 96 & 94,8 & 84,6 & & \\
\hline Total Centro & 99,7 & 100 & 98.9 & 96,9 & & \\
\hline Área Metropolitana & \multicolumn{4}{|c|}{ Cobertura residencial en energía eléctrica** } & & \\
\hline Total Aburrá Norte & 99,0 & 99,7 & 99,6 & 99,3 & \multirow{3}{*}{99,3} & \multirow{3}{*}{0,7} \\
\hline Total Aburrá Sur & 99,4 & 99,4 & 99,8 & 89,5 & & \\
\hline Total Centro & 99,2 & 100 & 99,9 & 98,8 & & \\
\hline Área Metropolitana & \multicolumn{4}{|c|}{ Cobertura residencial en alcantarillado*** } & & \\
\hline Total Aburrá Norte & 81,2 & 65,9 & 58,1 & 75,6 & \multirow{3}{*}{98,77} & \multirow{3}{*}{1,23} \\
\hline Total Aburrá Sur & 95,3 & 85,5 & 85,0 & 82,9 & & \\
\hline Total Centro & 99,8 & 99.9 & 96,9 & 95,7 & & \\
\hline Área Metropolitana & \multicolumn{4}{|c|}{ Cobertura residencial en gas natural $* * * *$} & & \\
\hline Total Aburrá Norte & 35,7 & 36,6 & 43,5 & 53,9 & \multirow{3}{*}{95,61} & \multirow{3}{*}{4,39} \\
\hline Total Aburrá Sur & 34,7 & 35,9 & 48,0 & 59,0 & & \\
\hline Total Centro & 53,0 & 63,1 & 72,5 & 75,2 & & \\
\hline Área Metropolitana & \multicolumn{4}{|c|}{ Cobertura residencial en internet***** } & & \\
\hline Total Aburrá Norte & 13,9 & 27,2 & 35,9 & 34,8 & \multirow{3}{*}{97,1} & \multirow{3}{*}{2,9} \\
\hline Total Aburrá Sur & 26,5 & 38,0 & 50,7 & 45,3 & & \\
\hline Total Centro & 31,3 & 46,7 & 56,0 & 55,1 & & \\
\hline
\end{tabular}




\section{Contexto munorat $A$}

\begin{tabular}{|c|c|c|c|c|c|c|}
\hline Área Metropolitana & \multicolumn{4}{|c|}{ Cobertura residencial en acueducto* } & \multicolumn{2}{|c|}{2018} \\
\hline Área Metropolitana & \multicolumn{4}{|c|}{ Cobertura residencial de aseo $* * * * * *$} & & \\
\hline Total Aburrá Norte & 90,7 & 94,5 & 91,8 & 93,0 & \multirow{3}{*}{97,0} & \multirow{3}{*}{3,0} \\
\hline Total Aburrá Sur & 92,3 & 97,4 & 94,4 & 87,5 & & \\
\hline Total Centro & 99,6 & 100 & 98.8 & 96,0 & & \\
\hline
\end{tabular}

* Mide la porción de viviendas que cuentan con acceso al servicio público de acueducto por red, sin incluir otras formas de abastecimiento ni conducción del agua. VCSA: Viviendas con servicio de acueducto. TV: Total de viviendas.

** Mide la porción de viviendas que cuentan con el servicio público de energía eléctrica. VSEE: Viviendas con servicio de energía eléctrica. TV: Total de viviendas.

*** Mide la porción de viviendas que cuentan con acceso al servicio público de alcantarillado por red, sin incluir otras formas tradicionales de eliminación de desechos líquidos. VSAL: Viviendas con servicio de alcantarillado. TV: Total de viviendas.

**** Mide la porción de viviendas que cuentan con acceso al servicio público de gas natural por red. VSGN: Viviendas con servicio de gas natural. TV: Total de viviendas.

$* * * * *$ Mide el porcentaje de viviendas que cuentan servicio de internet, por unidad geográfica. VSIN: Viviendas con conexión al servicio de Internet. TV: Total de viviendas.

****** Mide la porción de viviendas que cuentan con el servicio público de recolección de desechos sólidos. VSRR: Viviendas con servicio de aseo (recolección). TV: Total de viviendas.

Centro de Estudios del Área Metropolitana, Centro de estudios económicos regionales CEER de la ESAP y grupo de investigación Gobierno, Territorio y Cultura de Antioquia.

De los 1.102 municipios del país, 72 de ellos poseen los mejores índices de condiciones de vida. En Antioquia, los municipios con mejor ICV son aquellos que conforman el valle de Aburrá, las provincias administrativas y de planificación Cartama y San Juan y la de Aguas, Bosques y Turismo. Municipios que ganan en valorización de la tierra, turismo, asociación empresarial clúster, y mejores ingresos corrientes municipales por recaudo de impuesto predial, tránsito e industria y comercio (Iannetti, 2017).

Tabla 11.

ICV. Calidad de los servicios públicos

\begin{tabular}{ccccccccc}
\hline & Acueducto & \multicolumn{3}{c}{ Alcantarillado } & \multicolumn{3}{c}{ Energía } \\
\hline Bueno & Regular & Malo & Bueno & Regular & Malo & Bueno & Regular & Malo \\
\hline $93,6 \%$ & $4,8 \%$ & $1,1 \%$ & $91,5 \%$ & $6,8 \%$ & $0,8 \%$ & $95,2 \%$ & $4,1 \%$ & $0,5 \%$ \\
\hline & Gas & & & Internet & & Basuras & \\
\hline $92,25 \%$ & $4,56 \%$ & $0,28 \%$ & $66,6 \%$ & $25,8 \%$ & $5,3 \%$ & $84,7 \%$ & $11,4 \%$ & $1,9 \%$ \\
\hline
\end{tabular}

Centro de Estudios del Área Metropolitana, Centro de estudios económicos regionales CEER de la ESAP y grupo de investigación Gobierno, Territorio y Cultura de Antioquia 
Para conocer qué tan buena es la calidad de los servicios públicos básicos se les preguntó a los jóvenes universitarios de último semestre: ¿Cómo evalúa los servicios públicos domiciliarios de su localidad? Según la Tabla 11, el 93,6\% calificaron como bueno el servicio de acueducto. El 91,5\%, bueno el servicio de alcantarillado; el 95,2\%, bueno el servicio de energía; el 92,25\%, bueno el servicio de gas por red; el 66,6\%, bueno el servicio de internet y el 84,7\%, bueno el servicio de recolección de basuras. Datos que son muy satisfactorios, por cuanto muestran que los jóvenes universitarios del valle de Aburrá poseen buenos indicadores de calidad de vida en el consumo de servicios básicos domiciliarios (ver Tabla 11).

Los servicios de internet y de recolección de basuras mejoran la calidad de cobertura en más de un $90 \%$ cuando se toman en cuenta las evaluaciones regulares al servicio y las inexistentes, por ejemplo: el 92,4\% de los estudiantes afirman que el servicio es bueno y regular, el 2,4\% afirman que no tienen el servicio; ello implica que la cobertura es alta y de calidad aceptable. El 96,1\% de los estudiantes afirman poseer servicio de recolección de basuras de buena y regular calidad. Solo el 1,9\% afirmaron no tener el servicio. En otras palabras, el área ofrece servicios públicos domiciliarios con cobertura y calidad buenas (ver Tabla 11).

Si bien el servicio de telefonía móvil es ampliamente usado en la región, también lo es el servicio de telefonía fija también; el $82,3 \%$ afirman que es muy bueno el servicio mientras que el $8 \%$ dicen que es regular, en otras palabras, el 90,3\% poseen servicio de aceptable calidad. Solo el 6,9\% de los encuestados afirman no tener telefonía fija. De igual manera, en el disfrute de televisión por cable o TDT, el 93,1\% de los estudiantes afirman estar contentos o relativamente contentos con el servicio de televisión.

Tabla 12.

ICV. Cobertura y satisfacción en educación

\begin{tabular}{|c|c|c|c|c|c|c|c|c|c|}
\hline \multirow[t]{2}{*}{ Área Metropolitana } & \multicolumn{4}{|c|}{ Total cobertura en educación } & \multicolumn{5}{|c|}{ Satisfacción } \\
\hline & 2009 & 2011 & 2013 & 2015 & & & 201 & & \\
\hline Total Aburrá Norte. $4>x<5$ & 20,69 & 13,28 & 37,31 & 10,83 & & & & & \\
\hline Total Aburrá Sur. $4>x<5$ & 44,34 & 28,91 & 42,71 & 5,47 & 1 & 2 & 3 & 4 & 5 \\
\hline Total Centro. $4>x<5$ & 48,9 & 16,6 & 86 & 3,5 & & & & & \\
\hline
\end{tabular}




\section{Contexto Munosid}

\begin{tabular}{|c|c|c|c|c|c|c|c|c|c|}
\hline \multirow[t]{2}{*}{ Área Metropolitana } & \multicolumn{4}{|c|}{ Total cobertura en educación } & \multicolumn{5}{|c|}{ Satisfacción } \\
\hline & 2009 & 2011 & 2013 & 2015 & & & 201 & & \\
\hline Total Aburrá Norte. $5>\mathrm{x}<16$ & 57,41 & 47,45 & 54,98 & 39,26 & \multirow{6}{*}{$\begin{array}{l}1,7 \\
\%\end{array}$} & \multirow{6}{*}{$\begin{array}{l}1,1 \\
\%\end{array}$} & \multirow{6}{*}{$\begin{array}{l}13 \\
\%\end{array}$} & \multirow{6}{*}{$\begin{array}{c}34,8 \\
\%\end{array}$} & \multirow{6}{*}{$\begin{array}{c}47,8 \\
\%\end{array}$} \\
\hline Total Aburrá Sur. 5>x<16 & 74,44 & 58,96 & 68,92 & 51,9 & & & & & \\
\hline Total Centro. $5>x<16$ & 72,7 & 58,7 & 71,1 & 40,7 & & & & & \\
\hline $\begin{array}{l}\text { Total Aburrá Norte. } \\
17>x<21\end{array}$ & 13,9 & 24,25 & 21,53 & 5,46 & & & & & \\
\hline Total Aburrá Sur. 17>x<21 & 23,6 & 35,32 & 29,67 & 44,1 & & & & & \\
\hline Total Centro. $17>x<21$ & 26,5 & 37,3 & 34,7 & 15,7 & & & & & \\
\hline
\end{tabular}

Centro de Estudios del Área Metropolitana. Oficina de Planeación. Centro de estudios económicos regionales CEER de la ESAP y grupo de investigación Gobierno, Territorio y Cultura de Antioquia. 1 es poco satisfecho, 5 es muy satisfecho y 3 , regularmente satisfecho.

En el área metropolitana la cobertura en educación se ha estimulado en los últimos 17 años bajo el modelo de la economía de oferta. Los gobiernos municipales entregan becas de apoyo financiero a los mejores estudiantes de colegios públicos o con altos puntajes en las pruebas de Estado que desean ingresar a la universidad pública o privada. De igual manera, los municipios ofrecen ayudas financieras para estudios técnicos. Los estudiantes de bajos recursos que no logran buenos puntajes en las pruebas de Estado, el Fondo del Grupo EPM les ofrece créditos a una tasa de interés baja, con posibilidad de ser condonable por buen rendimiento académico. De igual manera, los municipios ofrecen becas de estudio a jóvenes de estrato socioeconómico bajo con buen promedio académico y excelentes resultados en pruebas de Estado. Son estrategias municipales de apoyo a la formación universitaria que buscan reducir las pérdidas de inversión doméstica en capital humano. El 82,6\% de los jóvenes universitarios de último semestre del valle de Aburrá afirman estar satisfechos y muy satisfechos con la calidad de la formación universitaria recibida. El 13\% dicen estar regularmente satisfechos. Solo el 2,8\% afirman estar insatisfechos o muy insatisfechos (ver Tabla 12).

De esta manera, las administraciones municipales del área metropolitana con su infraestructura de ciudad y su sistema de becas intentan retener la población joven, es decir, evitar la migración de jóvenes calificados MAC, y se vuelve además ciudad de destino de inmigrantes calificados, lo que garantiza la prosperidad futura de la región. En otras palabras, las alcaldías de las ciudades del área metropolitana complementan los programas de formación 
universitaria a las familias más pobres con becas de estudio a los mejores bachilleres y mejores pruebas de Estado Saber pro-ICFES, política del orden descentralizado que no reduce la oferta pública de universidades, por el contrario la aumenta, ya que el estudiante becado de escasos recursos puede elegir estudiar en universidades no públicas de alta calidad y alcanzar sus sueños de autorrealización (ver Figura 2).

\section{Jóvenes beneficiarios de programas sociales}

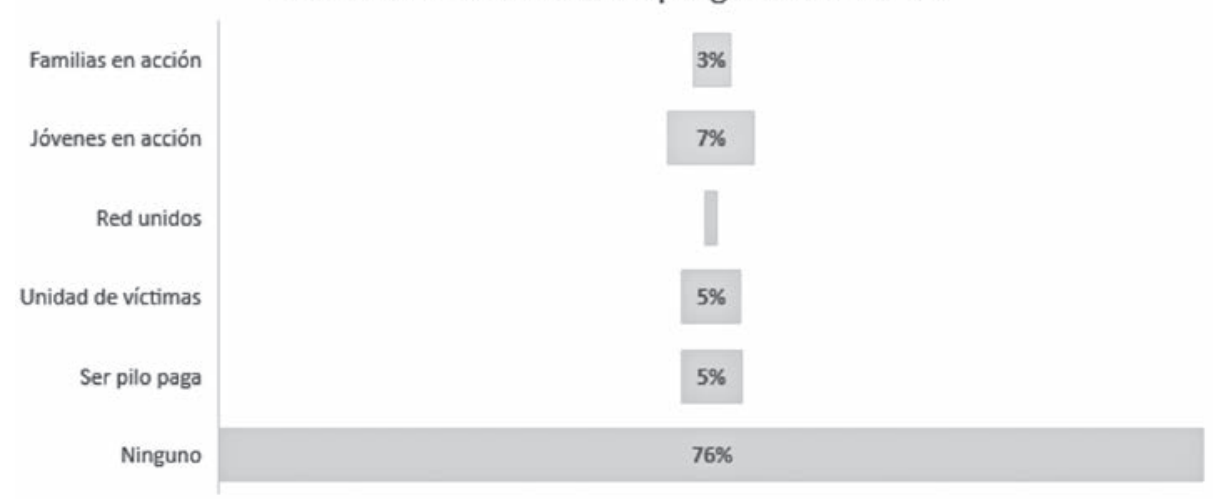

Figura 2. Jóvenes calificados beneficiarios.

Centro de estudios económicos regionales CEER de la ESAP y grupo de investigación Gobierno, Territorio y Cultura de Antioquia.

Afirmaciones sobre la ampliación de oferta ganan sentido cuando al menos un $24 \%$ de los estudiantes son beneficiarios de algún programa social, tales como: Más Familias en Acción, Jóvenes en Acción y Ser Pilo paga (Figura 2). El 76\% de los jóvenes estudiantes del área metropolitana no son beneficiarios de ningún programa social, lo que nos permite afirmar la existencia de una ampliación de oferta por parte del sector público de al menos el $24 \%$.

\section{Satisfacción con el equipamiento de ciudad: vecinos y movilidad}

A partir de los planteamientos de los teóricos de ciudad (Jacobs, 2011; Gehl, 2010; Pedersen, 2016), cabe preguntarse ¿son más humanas las ciudades que integran la gran ciudad del área metropolitana? Para responder esta pregunta, evaluamos la percepción de satisfacción de los jóvenes universitarios de último semestre, en este caso en relación con el disfrute de los recursos naturales, la calidad en los servicios de recreación y del vecindario. 


\section{Contexto munosed}

El $71,5 \%$ de los jóvenes afirman estar satisfechos y muy satisfechos con su vecindario. De hecho, el $64,8 \%$ de los jóvenes calificados afirman estar satisfechos y muy satisfechos con la seguridad del barrio en el que viven. El $26 \%$ afirman estar regularmente satisfechos. Solo el 9,2\% manifiestan estar insatisfechos y muy insatisfechos. Estos datos que arroja la investigación son muy significativos si se tienen en cuenta los problemas de violencia que han vivido los diferentes barrios y comunas del área metropolitana del valle de Aburrá, y es además muy relevante, toda vez que muestra que existe confianza en la gran ciudad del área metropolitana (ver Tabla 13).

Tabla 13.

Satisfacción con el equipamiento de ciudad

\begin{tabular}{cccc}
\hline Área Metropolitana & Recursos naturales & Esparcimiento y recreación & Vecindario \\
\hline 1 & $1,9 \%$ & $2,2 \%$ & $3,7 \%$ \\
\hline 2 & $3,2 \%$ & $4,5 \%$ & $5,9 \%$ \\
\hline 3 & $18,0 \%$ & $19,5 \%$ & $18,8 \%$ \\
\hline 4 & $40,5 \%$ & $35,1 \%$ & $30,1 \%$ \\
\hline 5 & $36,4 \%$ & $38,7 \%$ & $41,4 \%$ \\
\hline Total general & $100,0 \%$ & $100,0 \%$ & $100,0 \%$ \\
\hline
\end{tabular}

Centro de estudios económicos regionales CEER de la ESAP y grupo de investigación Gobierno, Territorio y Cultura de Antioquia. 1 es poco satisfecho, 5 es muy satisfecho y 3 , regularmente satisfecho.

En cuanto a los lugares de esparcimiento y de recreación que ofrece la gran ciudad del área metropolitana del valle de Aburrá, el 73,8\% de los jóvenes afirman estar satisfechos y muy satisfechos. Para ellos, los gimnasios al aire libre que ha construido el Área Metropolitana han sido un gran acierto para el encuentro comunitario en actividades lúdico-deportivas, el intercambio social de experiencias, el reconocimiento entre vecinos, la recuperación de espacios o puntos muertos bajo los puentes, y de espacios seguros para la socialización de jóvenes y adultos (Ver Tabla 13).

El 19,5\% de los jóvenes califican como regulares los lugares de esparcimiento y de recreación, principalmente los jóvenes universitarios de Copacabana, Caldas, La Estrella y Girardota. Sólo el 4,1\% afirman que en sus localidades no cuentan con lugares de esparcimiento y recreación. En cuanto a la satisfacción con el disfrute de los recursos naturales, el 76,9\% de los jóvenes manifiestan estar satisfechos y muy satisfechos; sin embargo, el 18\%, principalmente de 
los municipios de Medellín e Itagüí, manifiestan estar regularmente satisfechos y muy insatisfechos por la alta polución y el alto tráfico vehicular. Esto obliga a las administraciones públicas y al Área Metropolitana a buscar puntos administrativos de encuentro, tanto en el ordenamiento territorial como en matrículas de nuevos vehículos, creación de nuevas vías y usos de las vías públicas para la movilidad.

En relación con lo anterior, el 52,5\% de los jóvenes afirman que la calidad del control del tráfico para la movilidad es buena, mientras que el 32,5\% d afirman que la calidad del control de tráfico es regular, el 11,6\%, que es mala, y el 3,4\% la califica de inexistente, es decir, mala en el total global (ver Tabla 14). De estas cifras se desprende que hace falta control del tráfico para la movilidad. La gran ciudad del área metropolitana está saturada de vehículos. Medellín, Envigado, Itagüí, Sabaneta y Bello son las ciudades del área con más vehículos, más congestión vehicular, más accidentes de tránsito y más reportes de accidentes peatonales fatales, según el informe de mayo entregado por FundaPeatón en el 2018.

Tabla 14.

Satisfacción con el equipamiento para la movilidad

\begin{tabular}{ccccccccc}
\hline \multicolumn{2}{c}{ Calidad del tráfico } & \multicolumn{3}{c}{ Vías pavimentadas } & \multicolumn{2}{c}{ Señalización de vías } \\
\hline Bueno & Regular & Malo & Bueno & Regular & Malo & Bueno & Regular & Malo \\
\hline $52,5 \%$ & $32,5 \%$ & $15,0 \%$ & $70,0 \%$ & $25,2 \%$ & $4,8 \%$ & $67,2 \%$ & $25,7 \%$ & $5,2 \%$ \\
\hline
\end{tabular}

Centro de estudios económicos regionales CEER de la ESAP y grupo de investigación Gobierno, Territorio y Cultura de Antioquia.

De igual manera, los estudiantes encuestados de último semestre de la Escuela Superior de Administración Pública (ESAP) afirman que las cámaras de control de velocidad de tráfico no logran el objetivo esperado por la alta existencia de vehículos, que sobrepasa la estructura vial disponible del área metropolitana y no permite excesos de velocidad. Lo que las fotomultas generan es gananciaa a empresarios que en su momento enajenaron el espacio público para el beneficio privado y no social.

En relación con las vías pavimentadas, el $70 \%$ de los jóvenes universitarios encuestados afirman que son buenas, el 25,2\% dicen que son regulares, el 3,8\%, que son malas y el $1 \%$, que no existen; podríamos decir, entonces, que el $4,8 \%$ de las vías están en mal estado. En cuanto a la señalización de las vías para facilitar 


\section{Contexto minos $A$}

la movilidad, coadyuvar a la disminución de accidentes, ayudar a la correcta circulación de vehículos y a la movilidad de los peatones, el $67,2 \%$ de los jóvenes afirman que son buenas, el 25,7\%, que son regulares, el 5,2\%, que son malas y el 1,9\% afirman que son inexistentes (ver Tabla 14).

Tabla 15.

Satisfacción con los espacios peatonales y los escenarios deportivos

\begin{tabular}{cccccccc}
\hline \multicolumn{3}{c}{ Escenarios deportivos } & \multicolumn{4}{c}{ Aceras peatonales } \\
\hline Bueno & Regular & Malo & No tiene & Bueno & Regular & Malo & No tiene \\
\hline $81,3 \%$ & $16,2 \%$ & $1,8 \%$ & $0,7 \%$ & $67,1 \%$ & $29,1 \%$ & $2,7 \%$ & $1,1 \%$ \\
\hline
\end{tabular}

Centro de estudios económicos regionales CEER de la ESAP y grupo de investigación Gobierno, Territorio y Cultura de Antioquia.

Según la Tabla 15, respecto de las aceras peatonales para la movilidad peatonal segura, el $67,1 \%$ de los estudiantes afirman que son buenas, incluso están señalizadas para personas invidentes y de movilidad reducida; sin embargo, para el 29,1\% son regulares, porque carecen de espacios para el peatón. De acuerdo con FundaPeatón, la economía informal se apropió de los espacios.

En otras palabras, el equipamiento de infraestructura vial del área metropolitana es relativamente bueno, pues logra abastecer necesidades sociales y dar una amplia cobertura.

En cuanto a los escenarios deportivos, el 81,3\% de los estudiantes dicen que son buenos, el área metropolitana se caracteriza por tener abundantes escenarios deportivos: excelentes canchas de balompié, voleibol y basquetbol. Para el $16,2 \%$ son regulares. Mientras que el $0,7 \%$ dicen que no tienen y el $1,8 \%$ que son malas. En conclusión, podemos afirmar que el área metropolitana cuenta con buenos y abundantes escenarios deportivos (ver Tabla 15).

\section{Satisfacción con el equipamiento de ciudad: promoción de la cultura}

Los escenarios culturales sirven para la buena formación profesional y cultural de los ciudadanos y aportan a que se genere una ciudadanía ética, respetuosa del otro y de lo otro. En cuanto a los escenarios culturales, el $66,4 \%$ de los jóvenes estudiantes de último semestre universitario afirman que el área metropolitana posee buenas bibliotecas, principalmente en Medellín, Caldas, Envigado e Itagüí; el 22,9\% afirman que son regulares, sobre todo los estudiantes de Sabaneta y Bello; el 4,5\%, que son malas, especialmente los estudiantes 
de los municipios de Girardota y Copacabana, otros afirman que no tienen, principalmente los estudiantes encuestados de los corregimientos. De manera general, podría concluirse que el área metropolitana logra un cubrimiento relativamente bueno en un $89,3 \%$ (ver Tabla 16).

Tabla 16.

Satisfacción con los espacios culturales

\begin{tabular}{|c|c|c|c|c|c|c|c|}
\hline \multicolumn{3}{|c|}{ Calidad de las bibliotecas } & Bueno & Regular & Malo & No tiene & Total general \\
\hline \multicolumn{3}{|c|}{ Valle de Aburrá } & $66,4 \%$ & $22,9 \%$ & $4,5 \%$ & $6,2 \%$ & $100,0 \%$ \\
\hline \multicolumn{2}{|c|}{ Teatros } & \multicolumn{2}{|c|}{ Parques culturales } & \multicolumn{2}{|c|}{ Museos } & \multicolumn{2}{|c|}{ Casa de la cultura } \\
\hline Sí & No & Sí & No & Sí & No & Sí & No \\
\hline $61,6 \%$ & $38,4 \%$ & $83,0 \%$ & $17,0 \%$ & $62,9 \%$ & $37,1 \%$ & $71,4 \%$ & $28,6 \%$ \\
\hline
\end{tabular}

Centro de estudios económicos regionales CEER de la ESAP y grupo de investigación Gobierno, Territorio y Cultura de Antioquia.

En cuanto a la oferta de recreación y cultura, el área metropolitana logra una excelente cobertura con los parques culturales y recreativos Andrés Bello, Débora Arango, Fernando González, El Dorado, Arví, Marco Fidel Suárez, Casa de la Memoria, Parque Explora, los Cedezos, Uvas, entre otros. E1 83\% de los estudiantes de último semestre afirman disfrutar de dichos recursos, el $71,4 \%$ afirman que en sus municipios hay Casa de la Cultura, el 61,6\% afirman que tienen teatros y el 62,9\%, museos (ver Tabla 16).

Más del 28\% de los estudiantes afirman que en sus municipios no hay teatros ni museos, lo cual no deja de ser relevante por tratarse de instituciones promotoras de arte musical, artes escénicas y de formación cultural. Los municipios que menos equipamiento de ciudad cultural tienen, afirman los estudiantes encuestados, son: Girardota, Copacabana, Barbosa y La Estrella.

En otras palabras, el área metropolitana del valle de aburrá logra que aproximadamente el $67,89 \%$ del capital humano de alta calidad que forma permanezca en el territorio. Este dato es muy positivo, por cuanto de él se deduce que los jóvenes universitarios de último semestre creen en el desarrollo de la gran ciudad del área metropolitana, y más o menos la mitad de ellos contestaron que por el adecuado desarrollo municipal. 


\section{Contexto minos $A$}

\section{Felicidad subjetiva}

La felicidad subjetiva se refiere a la valoración individual que cada consumidor da al disfrute de bienes que demanda, es una valoración microeconómica que puede cambiar con los estados de ánimo o de riqueza de la persona en concreto, como lo hace el índice de felicidad de Pemberton (Beytía y Calvo, 2011). Noah Harari afirma que "lo subjetivo es algo que existe en función de la conciencia y creencia de un único individuo y desaparece o cambia si este individuo concreto cambia sus creencias" (2015, p.136).

Por el contrario, la felicidad intersubjetiva da cuenta de las relaciones sociales propias de los estados sociales de derecho; de la capacidad de asociación que tienen los individuos para la consecución del bien común. "Lo intersubjetivo es algo que existe en el seno de la red de comunicación que conecta la conciencia subjetiva de muchos individuos" (Harari, 2015, p.136).

Pero, si bien tanto el orden social como el político han sido transformados por los avances de la ciencia, Yuval Noah Harari en su libro De animales a dioses se pregunta: ¿somos realmente más felices? ¿Es realmente el mundo un mejor lugar para vivir? Existe una correlación positiva entre capacidades humanas y felicidad, afirma Harari, la cual se ha visto reflejada en la disminución de enfermedades y en aumento de la edad promedio de vida; por ejemplo, la medicina moderna ha logrado reducir en los últimos doscientos años la mortalidad infantil del $33 \%$ a menos del $5 \%$, pero ¿somos subjetivamente felices?

\section{Satisfacción con el proyecto de vida}

Según la Tabla 17, el 70,9\% de los jóvenes universitarios del último semestre del área metropolitana del valle de Aburrá poseen un proyecto de vida, el $24,1 \%$ no tienen un proyecto de vida y el $5 \%$ no respondieron la pregunta, principalmente mujeres. No obstante, son las mujeres las que más afirman tener un proyecto de vida $\mathrm{y}$, a su vez, las que menos afirman no tener un proyecto de vida. 
Tabla 17.

Felicidad subjetiva. Proyecto de vida

\begin{tabular}{cccc}
\hline ¿Posee usted algún proyecto de vida? & Hombres & Mujeres & Total general \\
\hline N/R & $3,6 \%$ & $5,4 \%$ & $5,0 \%$ \\
\hline Sí & $69,9 \%$ & $72,8 \%$ & $70,9 \%$ \\
\hline No & $26,5 \%$ & $21,8 \%$ & $24,1 \%$ \\
\hline Total general & $100,0 \%$ & $100,0 \%$ & $100,0 \%$ \\
\hline
\end{tabular}

Centro de estudios económicos regionales CEER de la ESAP y grupo de investigación Gobierno, Territorio y Cultura de Antioquia.

En cuanto a los proyectos de vida, figuran con mayor porcentaje ser profesionales $(39,5 \%)$ y ser emprendedores $(11,6 \%)$, mientras el $8,2 \%$ poseen un proyecto laboral. Un porcentaje muy representativo, 33,5\%, se abstuvieron de responder la pregunta (ver Tabla 18). El porcentaje de emprendedores, aunque es bajo es muy representativo, ya que puede ser parte del indicador anual de nuevas empresas registradas en Cámara de Comercio, y de la tasa de crecimiento anual de nuevas ideas de emprendimiento atendidas en los parques de innovación o de cultura emprendedora (INNova, Rutan ), o simplemente de las tasas anuales de crecimiento industrial de la ciudad con fines de exportación.

Tabla 18.

Proyecto de vida por género

\begin{tabular}{ccccccc}
\hline Proyecto de vida & Profesional & Familiar & Laboral & Emprendimiento & N/R & Total \\
\hline Hombres & $20,4 \%$ & $4,1 \%$ & $4,6 \%$ & $7,7 \%$ & $16,1 \%$ & $52,9 \%$ \\
\hline Mujeres & $19,4 \%$ & $3,1 \%$ & $3,8 \%$ & $4,3 \%$ & $16,4 \%$ & $47,0 \%$ \\
\hline Total general & $39,8 \%$ & $7,2 \%$ & $8,4 \%$ & $12,0 \%$ & $32,5 \%$ & $99,9 \%$ \\
\hline
\end{tabular}

Centro de estudios económicos regionales CEER de la ESAP y grupo de investigación Gobierno, Territorio y Cultura de Antioquia.

En la Tabla 18 se obsérva que, por género, persiste la tendencia en el hombre de ser empresario y emprendedor, la mujer, en cambio, tiende a ser menos aventurera, más conservadora, es decir, asume menos riesgos, como lo muestra el estudio sobre la dignidad de género en el mercado laboral colombiano(Muñoz, 2014). De igual manera se mantiene la tendencia observada, es decir, "a mayor desarrollo local más hombres estudian; por el contrario, a menor desarrollo 


\section{Contexto minosid}

local más mujeres buscan estudiar". Tendencia que puede ser explicada por razones económicas, culturales y de género (Muñoz, 2014).

Ante la pregunta, ¿qué tan satisfecho está usted con su proyecto de vida? El 96,2\% de los jóvenes universitarios afirman estar satisfechos y muy satisfechos. En otras palabras, están completamente satisfechos con las decisiones tomadas para el logro de sus metas. De allí que ante la pregunta: ¿realizaría su proyecto de vida en su municipio de residencia laboral y de estudios? El 71,9\% de los hombres y el $65,9 \%$ de las mujeres dicen que sí. El 27\% dicen que no, sino que migrarían a otras ciudades y países.

Del $80,5 \%$ de los jóvenes estudiantes que afirman dejar el área metropolitana para realizar su proyecto de vida, el 58\% afirman regresar para vivir y para trabajar. Es decir que el área metropolitana les genera sentimientos de pertenencia, por lo que logra retener el $67,89 \%$ de los jóvenes que forma (ver Tabla 19). Incluso cuando se preguntó: ¿qué tan satisfecho se siente usted viviendo en el área metropolitana?, el 47,9\% respondieron que muy satisfechos, el 34,4\%, satisfechos y el $12,4 \%$, regularmente satisfechos. Se observa que el $82,3 \%$ están plenamente satisfechos. Estos resultados de investigación permiten afirmar que los jóvenes universitarios creen en su gran ciudad llamada área metropolitana.

Tabla 19.

Sentido de pertenencia

\begin{tabular}{cccc}
\hline Volvería a: & Hombres & Mujeres & Total \\
\hline Trabajar & $14,4 \%$ & $10,5 \%$ & $24,9 \%$ \\
\hline Pasear & $14,0 \%$ & $12,4 \%$ & $26,4 \%$ \\
\hline Vivir & $19,1 \%$ & $15,6 \%$ & $34,7 \%$ \\
\hline No volvería & $1,5 \%$ & $0,8 \%$ & $2,3 \%$ \\
\hline No contesta & $4,3 \%$ & $7,4 \%$ & $11,7 \%$ \\
\hline Total & $53,3 \%$ & $46,7 \%$ & $100,0 \%$ \\
\hline
\end{tabular}

Centro de estudios económicos regionales CEER de la ESAP y grupo de investigación Gobierno, Territorio y Cultura de Antioquia.

Tales sentimientos de arraigo o de confianza parecen también ser fruto de las buenas acciones políticas, miremos por qué. En primer lugar, ante la pregunta ¿cómo evalúa usted la calidad en los servicios de seguridad de la policía? El 
$48,3 \%$ de estos jóvenes universitarios afirman que es muy buena, mientras el $36,1 \%$ dicen que es regular. Obsérvese que la confianza en la policía es superior a la no confianza, ya que el $13,3 \%$ dicen que la calidad en los servicios de seguridad de la policía es mala y el $2,4 \%$, que no existe. En otras palabras, la confianza en las acciones de seguridad de la policía es relativamente buena, lo que facilita el arraigo para el progreso de la ciudad (ver Tabla 20).

Tabla 20.

Satisfacción con la administración de la ciudad

\begin{tabular}{ccccc}
\hline Satisfacción con: & Gestión del Alcalde & Clase política & $\begin{array}{c}\text { Progreso } \\
\text { económico }\end{array}$ & Policía \\
\hline 1 & $10,2 \%$ & $12,9 \%$ & $6,8 \%$ & \multirow{2}{*}{$15,6 \%$} \\
\hline 2 & $8,3 \%$ & $10,5 \%$ & $6,7 \%$ & \\
\hline 3 & $30,8 \%$ & $33,4 \%$ & $33,5 \%$ & $36,1 \%$ \\
\hline 4 & $29,4 \%$ & $25,2 \%$ & $29,1 \%$ & \multirow{2}{*}{$48,3 \%$} \\
\hline 5 & $21,3 \%$ & $18,0 \%$ & $23,9 \%$ & \\
\hline Total general & $100,0 \%$ & $100,0 \%$ & $100,0 \%$ & $100,0 \%$ \\
\hline
\end{tabular}

Centro de estudios económicos regionales CEER de la ESAP y grupo de investigación Gobierno, Territorio y Cultura de Antioquia. 1 es poco satisfecho. $\mathbf{5}$ es muy satisfecho. 3 regularmente satisfecho.

En segundo lugar, el 53\% de los estudiantes encuestados afirman estar satisfechos y muy satisfechos con el progreso económico de la región y el 33,5\% califican de regular el progreso económico de los municipios del área. En otras palabras, el 86,5\% confían en el progreso económico de la ciudad (ver Tabla 20).

En tercer lugar, el 50,7\% de los jóvenes universitarios califican la gestión de los alcaldes del área metropolitana de satisfactoria y muy satisfactoria. Las de menor calificación son Barbosa y Bello. Las de mayor satisfacción son Medellín, Sabaneta y Envigado, y las de regular satisfacción, Itagüí, Caldas y Girardota. Para el 30,8\% de los jóvenes universitarios la gestión de sus alcaldes ha sido regular y para el $18,5 \%$ ha sido insatisfactoria y muy insatisfactoria, principalmente por actos de corrupción. Los jóvenes califican y evalúan su satisfacción con la clase política en función de la gestión de los alcaldes. De allí que para Barbosa y Bello afirmen estar insatisfechos con la clase política; por el contrario, Medellín, Sabaneta y Envigado están satisfechos con los líderes políticos (ver Tabla 20). 


\section{Contexto munosed}

\section{Satisfacción con el uso del tiempo libre}

Si bien el 74,7\% de los jóvenes universitarios del valle de Aburrá poseen un proyecto de vida, el 39,5\% de los estudiantes encuestados dedican gran parte del tiempo al ocio no creativo: disfrutar con amigos, jugar (juegos de mesa, video juegos), descansar, escuchar música, ver televisión, chatear a través de páginas web; en otras palabras, a disfrutar sin preocupaciones de deberes. El $25,5 \%$ dedican su tiempo libre a hacer deportes, a mantenerse saludables; el $3,3 \%$ a trabajar, y el $25,8 \%$ al ocio creativo: leer, estudiar, realizar actividades culturales (ver Tabla 21).

Tabla 21.

Uso del tiempo libre por género

\begin{tabular}{cccccccc}
\hline Actividades & Deportes & Ocio & Culturales & Educación & Trabajo & N/R & Total \\
\hline Hombres & $15,0 \%$ & $21,3 \%$ & $2,0 \%$ & $11,2 \%$ & $1,9 \%$ & $2,5 \%$ & $53,8 \%$ \\
\hline Mujeres & $10,6 \%$ & $18,3 \%$ & $1,2 \%$ & $11,4 \%$ & $1,4 \%$ & $3,3 \%$ & $46,2 \%$ \\
\hline Total & $25,5 \%$ & $39,6 \%$ & $3,2 \%$ & $22,6 \%$ & $3,3 \%$ & $5,8 \%$ & $100,0 \%$ \\
\hline
\end{tabular}

Centro de estudios económicos regionales CEER de la ESAP y grupo de investigación Gobierno, Territorio y Cultura de Antioquia.

Para el índice IFI de Medellín, el uso del tiempo libre como búsqueda de felicidad con el entorno mostraría que el $28,7 \%$ de los jóvenes universitarios de último semestre del valle de Aburrá lo dedican a actividades culturales y de deporte y el 39,5\%, al ocio lúdico, a los logros del encuentro de la interioridad o de los estados de felicidad (ver Tabla 21).

De acuerdo con las respuestas encontradas podemos afirmar, siguiendo los análisis del psicólogo Pemberthon, que los jóvenes universitarios de último semestre de carrera del valle de Aburrá tienden a mostrar una convivencia en entornos sanos, es decir, viven en una sociedad sana y con grandes valores familiares, con relaciones en las que prima el ser humano sobre las riquezas materiales. En otras palabras, más del $85 \%$ de estos universitarios poseen felicidad subjetiva alta; incluso superior al $42,66 \%$, con alta experiencia de felicidad sentida, como ya lo había planteado el estudio del IFI de Medellín en el 2016.

Sin embargo, el 93,2\% de los jóvenes universitarios de último semestre del valle de Aburrá afirman no trabajar o pertenecer a grupos sociales o comunitarios de su ciudad. Es decir que no ponen al servicio de la comunidad o de su localidad los 
conocimientos adquiridos durante todo el tiempo de su formación académica; no devuelven a la localidad, para su progreso, todos los esfuerzos fiscales y administrativos de la ciudad; no son solidarios, parecen estar en función de sí mismos y no del conjunto social.

Ausencias del deber de la solidaridad de los jóvenes universitarios son el producto de un abandono estatal en la formación de la ética ciudadana de la corresponsabilidad, ética que desde hace 2 años se viene fortaleciendo siguiendo los buenos resultados de la Cultura Metro, con eslóganes como "El centro sos vos", incluso a través de obras de teatro con títeres a jóvenes y adolescentes para que amen y cuiden su ciudad y su sistema Metro.

El gasto público realizado por las diferentes administraciones públicas del área metropolitana en: movilidad, educación, salud, seguridad, cultura, hospitales, plazas públicas, paseos peatonales, etcétera, se lleva a cabo sin una exigencia de corresponsabilidad ciudadana. Es necesario que el $24 \%$ de los jóvenes universitarios que son beneficiarios de algún programa para sus estudios -como Más Familias en Acción, Jóvenes en Acción y Ser Pilo Paga- devuelvan el gasto público en ellos invertido a través de la enseñanza a jóvenes de décimo y undécimo grados escolares en áreas de las ciencias exactas como: matemáticas, física y química, en idiomas como el español y el inglés, así como en música, arte y poesía. Es necesario acabar con la cultura del regalo y formar en la ciudadanía de los derechos y deberes, de la corresponsabilidad, como lo plantean Muñoz Cardona (2017) y Camps y Giner (2014).

\section{Conclusiones}

¿Qué tan feliz se siente el joven universitario de último semestre de vivir en el área metropolitana del valle de Aburra? El 84,1\% de los hombres y el $80,3 \%$ de las mujeres respondieron que están satisfechos y muy satisfechos. Es decir, aman el área metropolitana del valle de Aburrá, mientras el 11,2\% de los hombres y el 13,9\% de las mujeres son regularmente felices. Eso implica que el $94,7 \%$ del total de los jóvenes universitarios de último semestre del área metropolitana del valle de Aburrá son felices de vivir en esta gran ciudad; solo el 5,2\% manifiestan estar muy insatisfechos.

Las razones principales de sus felicidades son: Satisfacción personal, porque ven cumplir sus sueños, sus anhelos de autorrealización (los hombres en un $16,18 \%$ y las mujeres en un $11,72 \%$ ); bienestar fisico y emocional, lo que implica la sociabilidad con los otros (los hombres en un 7,53\% y las mujeres en un 5,03\%). 


\section{Contexto Minosid}

Es notable que para los jóvenes no priman las riquezas materiales sino los logros de superación y de bienestar emocional que les brinda el entorno, lo que va en línea con la respuesta a la pregunta: ¿Cuál es la persona o personaje que usted más admira? El 26,9\% admiran a científicos, escritores y artistas, principalmente por el ejemplo de superación $(29,7 \%)$, el buen desempeño profesional $(15,5 \%)$ y por su inteligencia y disciplina $(9,1 \%)$. Para el $17,7 \%$ la persona que más admiran son sus padres y familiares por el buen ejemplo. El 15,8\%, admiran a políticos como Nelson Mandela y Mahatma Gandhi por su amor a la comunidad $(9,7 \%)$, entre otras razones.

Se concluye en términos de la felicidad subjetiva, siguiendo los métodos de análisis del psicólogo Pemberthon, que los jóvenes universitarios de último semestre del Valle de Aburrá tienden a mostrar una convivencia dentro de entornos sanos, es decir, viven en una sociedad sana y con grandes valores familiares, en la que prima más la relación con el otro que las tenencias materiales. En otras palabras, más del $94 \%$ de estos jóvenes poseen felicidad subjetiva alta.

En términos de felicidad intersubjetiva se concluye que las ciudades del área metropolitana del valle de Aburrá son ciudades con una muy buena cobertura en los servicios básicos domiciliarios con calidad, en más de un $90 \%$. Por lo que para este ítem de P1 recibe una calificación de 4,5 (Cuatro, Cinco)

En cuanto a la estructura de los municipios en oferta de servicios sociales -educación, bibliotecas, museos, parques recreativos, y de recursos naturales-, los estudiantes universitarios de último semestre de las principales ciudades del valle de Aburrá afirman estar satisfechos y muy satisfechos en más de un $80 \%$. Incluso el $71,5 \%$ de estos jóvenes afirman poseer un muy buen vecindario, a pesar de la violencia que sufren algunos barrios de Itagüí y de Medellín. Por lo que este ítem recibe una calificación de 4,0 (Cuatro, Cero).

Ocho de las ciudades del valle de Aburrá ofrecen a sus ciudadanos buen gobierno y buenas expectativas de crecimiento económico, sin embargo, las ciudades de Barbosa y Bello no ofrecen a sus ciudadanos las mismas expectativas de crecimiento económico y de buen gobierno, por lo tanto los jóvenes universitarios de último semestre manifiestan su insatisfacción general con la clase política de sus municipios. Asimismo, el 71,9\% de los jóvenes universitarios de último semestre afirman realizar su proyecto de vida en el valle de Aburrá, es decir, las ciudades del área metropolitana logran retener más del 59,5\% del capital formado durante de 17 años. En otras palabras, reducen la fuga de cerebros o la migración de la población altamente calificada MAC. 
De igual manera, el 64,8\% de los jóvenes universitarios de último semestre se sienten satisfechos y muy satisfechos con la seguridad de la zona residencial en la que viven; incluso el 48,3\% de los estudiantes encuestados califican de buena la calidad de las acciones de seguridad de la policía, es decir, confían en ella. Por lo que la evaluación a este ítem es 3,5 (Tres, Cinco)

$$
\text { Felicidad }=0.4\left(4.5=P_{1}\right)+0.3\left(.0=P_{2}\right)+0.3\left(3.5=P_{3}\right) \approx 4.05
$$

Por lo tanto, los jóvenes universitarios de último semestre del valle de Aburrá poseen una felicidad intersubjetiva de beneficios de ciudad de 4,05. Para mejorar en el índice de felicidad intersubjetiva es necesario mejorar la vitalidad comunitaria y la gobernanza. Es decir, la participación de los jóvenes en el crecimiento de la comunidad (DANE, 2016). Finalmente, en conformidad con todo lo anterior, podemos afirmar con Rey (2015/07/25) que "la felicidad sí se puede medir".

\section{Referencias}

Beytía, P. y Calvo, E. (2011). ¿Cómo medir la felicidad? Revista Claves de Política Pública, (4), 1-10. http://dx.doi.org/10.2139/ssrn.2302809

Camps, V. y Giner, S. (2014). Manual de Civismo. Barcelona: Ariel.

Cervera, C. (2012). La eudaimonía en Aristóteles y su posible aplicación en la actualidad. Una reflexión sobre la felicidad a partir de la contraposición de la noción actual del término con el concepto aristotélico de eudaimonía (Tesis de grado en Licenciatura en Humanidades). Universidad Oberta de Catalunya.

Departamento Administrativo Nacional de Estadísticas (DANE). (2016). Primer Diagnóstico de Felicidad para Colombia. Presentación del director del DNP Simón Gaviria Muñoz. Bogotá.

"En Medellín así es la experiencia ciudadana de felicidad sentida" (20 de marzo de 2017). El Mundo.com. Sección: Estilos de vida. Recuperado de https://www.elmundo.com/noticia/En-Medellin-asi-es-la-experienciaciudadana-de-felicidad-sentida/48761

Gehl, J. (2010). Cities for People. Washington: Island Press.

Harari N., Y. (2015). De animales a dioses. Breve historia de la humanidad. Colombia: Debate. 


\section{Contexto Muñoz, A.}

Iannetti, M. (2017). Informe final de las propuestas de implementación acordadas en los talleres de aprendizaje sobre las provincias en Italia y su aplicación en la provincia administrativa y de planificación (PAP) de Cartama. Medellín: Departamento Administrativo de Planeación, Gobernación de Antioquia. Pasante Internacional del King's College of London.

Jacobs, J. (2011). Muerte y vida de las grandes ciudades. Madrid: Capitán Swin Libros.

Maslow, A. H. (2008). La personalidad creadora. Barcelona: Kairós.

Muñoz Cardona, Á. E. (2014). Gender Dignity in the Colombian Labor Market (2000-2013). Open Journal in Political Science, 4(4), 195-207.

Muñoz, Á. E. (2017). Ética de responsabilidad ciudadana. (2.a ed.). Bogotá: Escuela Superior de Administración Pública. Facultad de Investigaciones.

Muñoz, Á. E. (2018). Desigualdad y pobreza. Área metropolitana del Valle de Aburrá, un caso ejemplar. Revista de Investigación en Derecho y Ciencias Políticas, INCISO, 20(1), 90-110.

Pedersen, M. (2016). Common Edge. 10 lessons learned by re-reading Jean Jacobs. Recuperado de https://commonedge.org/10-lessons-learned-byrereading-jane-jacobs/ [Consultado el 26 de abril de 2019].

Prieto, E. (Coord.). (2015). Plan de Gestión 2016-2019. Territorios integrados. Área Metropolitana del Valle de Aburrá. Medellín: Oficina de Planeación del Área Metropolitana del Valle de Aburrá.

Prieto, E. (2017). "La fuerza de la asociatividad". Boletín El Metropolitano del Valle de Aburrá. [En línea]. Editorial. Área Metropolitana del Valle de Aburrá. Recuperado de https://www.metropol.gov.co/

Restrepo S., N. (2011). Empresariado antioqueño y sociedad, 1940-2004: influencia de las élites patronales de Antioquia en las políticas socioeconómicas colombianas. Medellín: Universidad de Antioquia, Colección Clío.

Restrepo, M. E. (2010). La innovación como estrategia para mejorar la competitividad. Experiencia de éxito. Medellín: Metro de Medellín, Calidad de Vida. Medellín: Empresa de Transporte Masivo del Valle de Aburrá Limitada. Asamblea de Afiliados CCMA.

Rey, G. H. (2015, 25 de julio). La felicidad si se puede medir. Portafolio, Edición especial. 
Stiglitz, J. (2014). "La ciudad y las desigualdades". Conferencia de apertura, Foro Urbano Mundial. Medellín, 14 de abril de 2014. Alcaldía de Medellín.

Stiglitz, J., Sen, A. y Fitoussi, J. (2015). Informe de la Comisión sobre la Medición del Desarrollo Económico y del Progreso Social. Síntesis y recomendaciones. Francia: CMPEPS.

\section{Para citar este artículo:}

Muñoz, Á. (2019). Felicidad Urbana. Área metropolitana del Valle de Aburrá. En-Contexto, 7(11), 113-147. 